\title{
In situ SU-8 silver nanocomposites
}

\section{Fischer, Søren Vang; Uthuppu, Basil; Jakobsen, Mogens Havsteen}

\section{Published in:}

Beilstein Journal of Nanotechnology

Link to article, DOI:

10.3762/bjnano.6.168

Publication date:

2015

Document Version

Publisher's PDF, also known as Version of record

Link back to DTU Orbit

Citation (APA):

Fischer, S. V., Uthuppu, B., \& Jakobsen, M. H. (2015). In situ SU-8 silver nanocomposites. Beilstein Journal of Nanotechnology, 6, 1661-1665. https://doi.org/10.3762/bjnano.6.168

\section{General rights}

Copyright and moral rights for the publications made accessible in the public portal are retained by the authors and/or other copyright owners and it is a condition of accessing publications that users recognise and abide by the legal requirements associated with these rights.

- Users may download and print one copy of any publication from the public portal for the purpose of private study or research.

- You may not further distribute the material or use it for any profit-making activity or commercial gain

- You may freely distribute the URL identifying the publication in the public portal

If you believe that this document breaches copyright please contact us providing details, and we will remove access to the work immediately and investigate your claim 


\title{
In situ SU-8 silver nanocomposites
}

\author{
Søren V. Fischer ${ }^{*}$, Basil Uthuppu and Mogens H. Jakobsen
}

\author{
Letter \\ Address: \\ DTU Nanotech, Technical University of Denmark, \\ Anker Engelundsvej 1, 2800 Kgs. Lyngby, Denmark \\ Email: \\ Søren V. Fischer ${ }^{*}$ - soren.fischer@nanotech.dtu.dk \\ * Corresponding author \\ Keywords: \\ functional photoresist; in situ synthesis; metal nanoparticles; micro \\ and nanofabrication; nanocomposite
}

Beilstein J. Nanotechnol. 2015, 6, 1661-1665.

doi:10.3762/bjnano.6.168

Received: 11 February 2015

Accepted: 07 July 2015

Published: 30 July 2015

Associate Editor: P. Leiderer

C 2015 Fischer et al; licensee Beilstein-Institut.

License and terms: see end of document.

\begin{abstract}
Nanocomposite materials containing metal nanoparticles are of considerable interest in photonics and optoelectronics applications. However, device fabrication of such materials always encounters the challenge of incorporation of preformed nanoparticles into photoresist materials. As a solution to this problem, an easy new method of fabricating silver nanocomposites by an in situ reduction of precursors within the epoxy-based photoresist $\mathrm{SU}-8$ has been developed. $\mathrm{AgNO}_{3}$ dissolved in acetonitrile and mixed with the epoxy-based photoresist SU-8 forms silver nanoparticles primarily during the pre- and post-exposure soft bake steps at $95{ }^{\circ} \mathrm{C}$. A further high-temperature treatment at $300{ }^{\circ} \mathrm{C}$ resulted in the formation of densely homogeneously distributed silver nanoparticles in the photoresist matrix. No particle growth or agglomeration of nanoparticles is observed at this point. The reported new in situ silver nanocomposite materials can be spin coated as homogeneous thin films and structured by using UV lithography. A resolution of $5 \mu \mathrm{m}$ is achieved in the lithographic process. The UV exposure time is found to be independent of the nanoparticle concentration. The fabricated silver nanocomposites exhibit high plasmonic responses suitable for the development of new optoelectronic and optical sensing devices.
\end{abstract}

\section{Findings}

Noble metal nanoparticles (NPs) have been of high interest for many years as their unique properties make them useable in a large variety of applications [1]. The application of these NPs ranges from optical imaging, optoelectronics and electrochemistry to catalysts [2]. However, it is difficult to use such NPs in conjunction with standard top down micro- and nanofabrication processes as positioning and control of the nanoparticles are impossible to maintain [3]. Homogeneous polymeric thin film metal nanocomposites are therefore of great interest within micro- and nanofabrication [4-6]. The nanoparticles encased in a polymeric matrix should maintain their physical properties, while the nanocomposite can be structured by using standard fabrication methods allowing for the development of new optoelectronic and sensing devices. 
Metal nanoparticles in photoresists are also interesting within technologies for three-dimensional structuring as these can be used for fabrication of photonic crystals [7].

A good candidate for a polymeric matrix is the epoxy-based photoresist SU-8, which is widely used for making high-aspectratio structures [8]. SU-8 is good for optical sensors being highly transparent in the visible region [9] and also useful in biological sensing applications being quite biocompatible [10]. SU-8 is also well suited for direct laser writing and 3D structuring [11] although only 2D structures are considered in this work.

SU-8 thin films are deposited on wafers by using standard spin coating techniques [12]. However, high loadings of preformed NPs in the polymer change the rheological behaviour and might hinder the ability to use spin-coating for thin film nanocomposites $[13,14]$. Furthermore, it is difficult to obtain stable suspensions of preformed NPs in SU-8 without aggregation and phase separation.

In situ synthesis methods where the particles are formed directly within the polymeric matrix from a precursor can circumvent this problem. Here, we report a fast and simple method for fabricating homogeneous SU-8-based metal nanocomposite thin films with in situ generated silver nanoparticles. These composite materials can be deposited on wafers by using standard spin coating techniques and subsequently structured with UV lithography.

The nanocomposite is prepared by dissolving $\mathrm{AgNO}_{3}$ precursor in acetonitrile in a two-fold dilution series: $500 \mathrm{mg} \cdot \mathrm{mL}^{-1}$, $250 \mathrm{mg} \cdot \mathrm{mL}^{-1}, 125 \mathrm{mg} \cdot \mathrm{mL}^{-1}, 62.5 \mathrm{mg} \cdot \mathrm{mL}^{-1}, 31.3 \mathrm{mg} \cdot \mathrm{mL}^{-1}$, and $15.6 \mathrm{mg} \cdot \mathrm{mL}^{-1} \cdot 0.5 \mathrm{~mL}$ of the freshly prepared precursor solutions or $0.5 \mathrm{~mL}$ acetonitrile as reference is added to $4 \mathrm{~mL}$ of SU-8 2002, which is a formulation of SU-8 with cyclopentanone as the main solvent. $\mathrm{As} \mathrm{AgNO}_{3}$ is not soluble in cyclopentanone, acetonitrile is chosen as a co-solvent. $\mathrm{AgNO}_{3}$ precursor solutions with a concentration above $500 \mathrm{mg} \cdot \mathrm{mL}^{-1}$ are immiscible with SU-8 using the described protocol.

The SU-8 mixture is then spun on a $100 \mathrm{~mm}$ fused silica or silicon wafer, at $1500 \mathrm{rpm}$ for $1 \mathrm{~min}$ followed by heating at $95{ }^{\circ} \mathrm{C}$ on a hotplate for $10 \mathrm{~min}$. After heating, a UV exposure of $7.5 \mathrm{~min}$ is performed to cross-link the polymer followed by a post exposure bake at $95{ }^{\circ} \mathrm{C}$ on a hotplate for $10 \mathrm{~min}$. In case of structuring, a mask is used in soft-contact mode during the exposure and the wafer is then developed for $2 \mathrm{~min}$ in propylene glycol monomethyl ether acetate (PGMEA) [15] followed by rinsing with 2-propanol (IPA). After development or post exposure bake some of the wafers are further heated to $300{ }^{\circ} \mathrm{C}$ for $30 \mathrm{~min}$ on a hotplate. The UV exposure is done without any filters in the aligner.

The chosen co-solvent for the $\mathrm{AgNO}_{3}$ precursor, acetonitrile, is a mild reducing agent. This precursor solution must therefore be prepared fresh, and added to the SU-8 just before spin coating, to minimise unwanted formation of nanoparticles [13].

The used formulation of SU- 8 can be used for depositing thin films in the range of $1-1.8 \mu \mathrm{m}$ as documented by the spin curve shown in Figure 1. The resulting film thickness is smaller than with unmodified SU-8, but the thickness can be increased by using more viscous SU-8 formulations if desired.

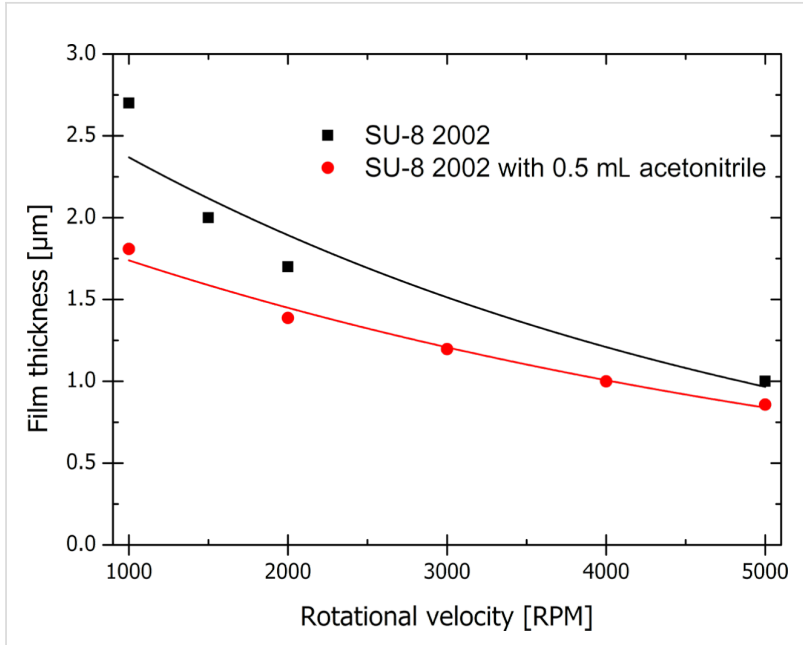

Figure 1: Spin curves for SU-8 2002 and SU-8 2002 with acetonitrile. The addition of acetonitrile results in a decreased film thickness compared to the unmodified SU-8.

Mostly, AgNPs are formed during the heat treatments before and after UV exposure. The exact process is not known as acetonitrile and the many constituents of SU-8 play a role in the NP formation. The AgNPs formed in the SU-8 polymer matrix show a clear plasmonic absorption [16] in the visible region as seen in Figure 2.

The high temperature post-exposure bake at $300^{\circ} \mathrm{C}$ resulted in the formation of densely populated silver nanoparticles in the polymer matrix. They appeared to be single nanoparticles entities, smaller than the clusters that formed during the baking steps at $95{ }^{\circ} \mathrm{C}$. This is evident from the UV-vis absorption spectra shown in Figure 3.

The plasmonic peak of a nanocomposite baked at $95{ }^{\circ} \mathrm{C}$ is broad, which indicates particles or agglomerates with a wide size distribution, whereas the peak corresponding to the composite material treated at $300{ }^{\circ} \mathrm{C}$ is sharper, enhanced and 


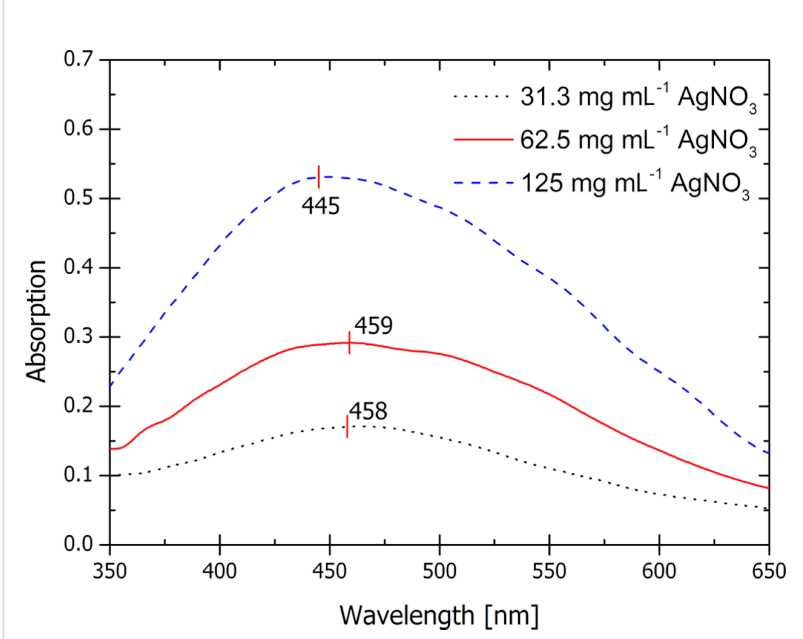

Figure 2: UV-vis absorption spectra of silver nanocomposites at silica wafers after post-exposure bake at $95^{\circ} \mathrm{C}$ with varying $\mathrm{AgNO}_{3}$ precursor concentrations. The absorption increases with increasing amounts of $\mathrm{AgNO}_{3}$ precursor added.

more defined with a $\lambda_{\max }$ of $434.5 \mathrm{~nm}$. The peak position at $434.5 \mathrm{~nm}$ is a typical value for the absorption band of AgNPs [17]. Also; this peak resembles the plasmonic peak obtained for AgNPs in cyclopentanone. The shoulder appearing at higher wavelengths for the nanocomposite indicates the retention of the AgNP clusters, formed during the lower temperature treatments. These results are visually corroborated in the SEM images shown in Figure 4.

The formation of AgNPs is confirmed with SEM by looking at the cross-sectional area of a fabricated nanocomposite wafer as shown in Figure 4. The images confirm that individual NPs of $25 \mathrm{~nm}$ in diameter are formed, although the randomly distributed NP clusters of roughly $80-100 \mathrm{~nm}$ are easy to spot when looking at the composite treated at $95{ }^{\circ} \mathrm{C}$. The SEM image

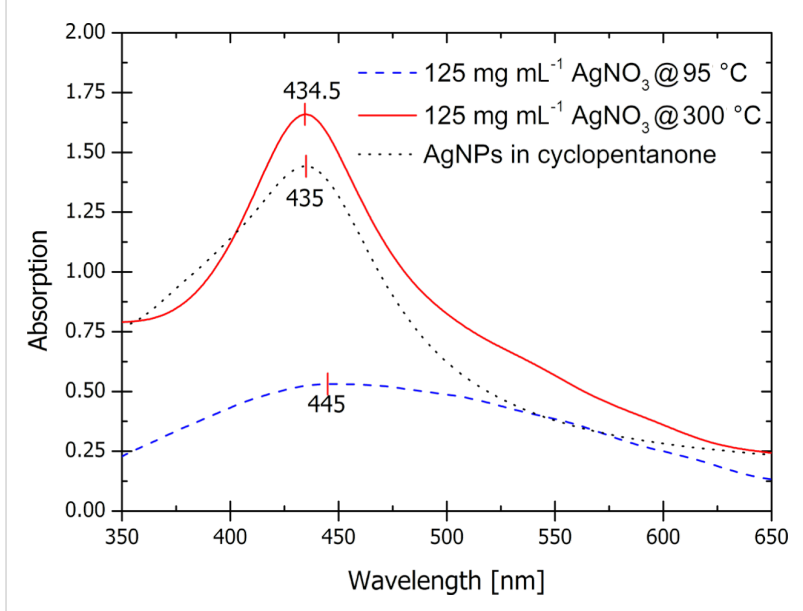

Figure 3: UV-vis absorption spectra of a nanocomposite on a silica wafer containing $0.5 \mathrm{~mL}$ of $125 \mathrm{mg} \cdot \mathrm{mL}^{-1} \mathrm{AgNO}_{3}$ precursor solution after different post-exposure heat treatments. Blue dashed curve after $95^{\circ} \mathrm{C}$ for $10 \mathrm{~min}$, red solid curve - after an additional $300^{\circ} \mathrm{C}$ for 30 min and black dotted curve - AgNPs in cyclopentanone for comparison.

further confirms that the additional heat treatment of $300{ }^{\circ} \mathrm{C}$ results in the generation of more $25 \mathrm{~nm}$ sized nanoparticles. It is important to note that further growth of already formed agglomerated NPs does not happen during this last heat treatment.

Structuring of the nanocomposite is important if to be used in micro- and nanofabrication. Although not fully optimized a resolution of $5 \mu \mathrm{m}$ is obtained using UV-lithography as shown in Figure 5.

The UV exposure results in the formation of a Lewis acid which cross-links the resist in the exposed areas [18]. The prolonged exposure of $7.5 \mathrm{~min}$ compared to a standard exposure time of $10 \mathrm{~s}$ is required because of the absorption and shadowing effects of the formed AgNPs. Further optimisation of the exposure time

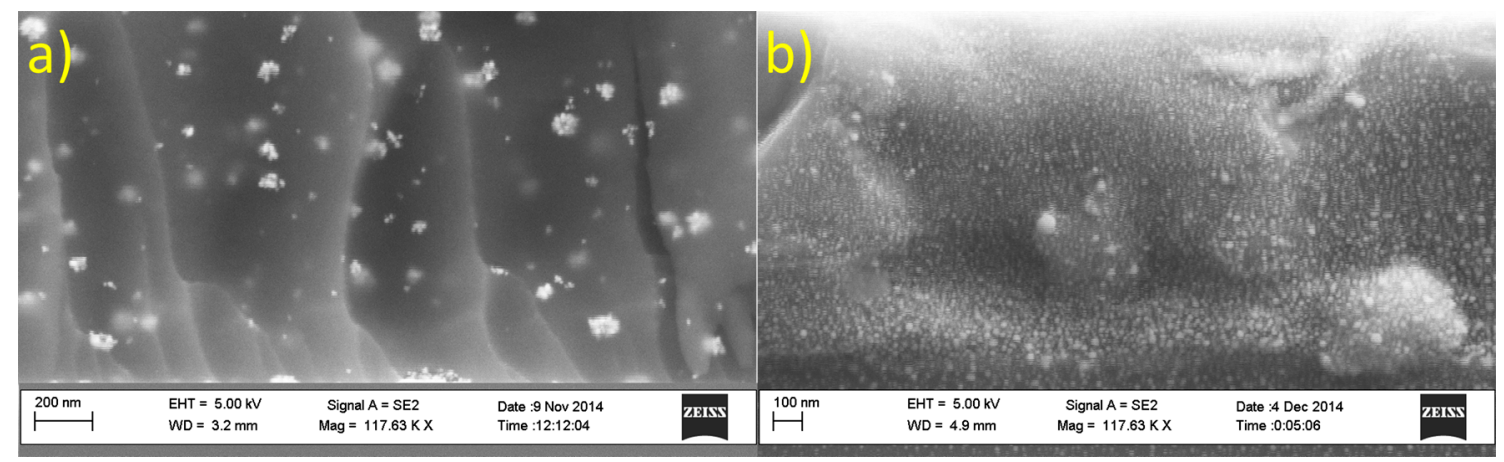

Figure 4: SEM images of a cross section of a nanocomposite on a silicon wafer containing $0.5 \mathrm{~mL}$ of $125 \mathrm{mg} \cdot \mathrm{mL}^{-1} \mathrm{AgNO}_{3} \mathrm{precursor}$ solution. a) after a post-bake at $95^{\circ} \mathrm{C}$ for $10 \mathrm{~min}$ and b) after an additional bake at $300^{\circ} \mathrm{C}$ for $30 \mathrm{~min}$. 


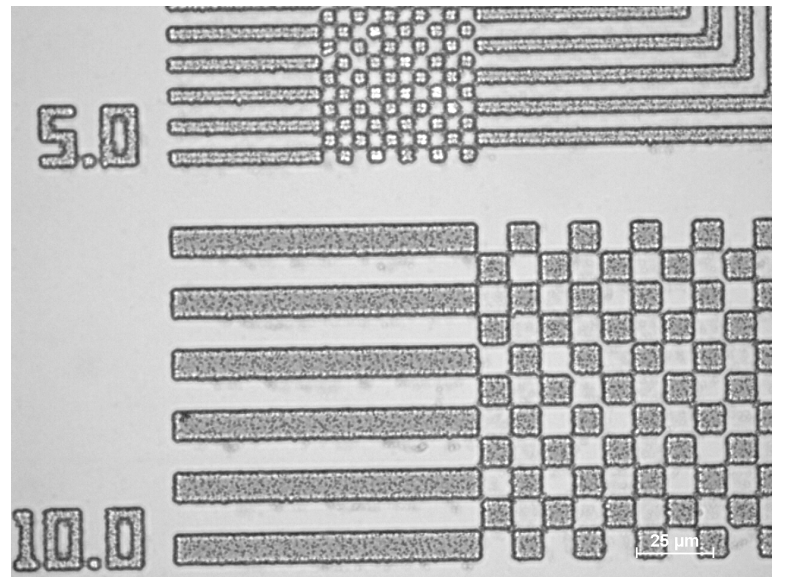

Figure 5: Microscope image at 50× magnification of a nanocomposite containing $0.5 \mathrm{~mL}$ of $125 \mathrm{mg} \cdot \mathrm{mL}^{-1} \mathrm{AgNO}_{3}$ precursor solution after structuring using UV lithography.

needs to be done for improving the currently obtained resolution of $5 \mu \mathrm{m}$. However, preliminary experiments show that the exposure time is independent of the added precursor solution for the structured nanocomposites with concentrations up to $125 \mathrm{mg} \cdot \mathrm{mL}^{-1} \mathrm{AgNO}_{3}$.

With a concentration of $250 \mathrm{mg} \cdot \mathrm{mL}^{-1}$ precursor solution added to the SU-8, larger amounts of homogeneously distributed micron-sized AgNP agglomerates are formed after the postexposure bake at $95{ }^{\circ} \mathrm{C}$. This is easily seen from the microscope image in Figure 6a. When the precursor solution concentration is increased to $500 \mathrm{mg} \cdot \mathrm{mL}^{-1}$, randomly distributed phase separated islands of $\mathrm{Ag}$, more than $100 \mu \mathrm{m}$ in size, are formed as shown in Figure 6b.
In conclusion, we have developed a method for making in situ SU-8 silver nanocomposites with use of the precursor $\mathrm{AgNO}_{3}$ dissolved in the SU-8 compatible solvent acetonitrile. The nanocomposite can easily be deposited and structured by using standard micro- and nanofabrication processes such as spin coating and UV lithography. A high resolution of $5 \mu \mathrm{m}$ has been achieved with UV lithography. The UV exposure time is found to be independent of the $\mathrm{AgNO}_{3}$ precursor concentration. We have shown that a bake at $300{ }^{\circ} \mathrm{C}$ results in further AgNP formation in the composite and not particle growth or agglomeration. The plasmonic absorption maximum is close to $435 \mathrm{~nm}$ and is independent of the $\mathrm{AgNO}_{3}$ precursor concentration up to $125 \mathrm{mg} \cdot \mathrm{mL}^{-1}$. The AgNPs formed in the SU-8 matrix is approximately $25 \mathrm{~nm}$ and distributed evenly in the composite matrix. At higher precursor concentrations, larger agglomerated NPs are dominant and large islands of phase separated Ag are formed in the composite.

\section{Experimental \\ Preparation of Ag NPs in cyclopentanone Materials}

Silver nitrate $\left(\mathrm{AgNO}_{3}, \geq 99.0 \%\right)$ and sodium borohydride $\left(\mathrm{NaBH}_{4}, \geq 98.0 \%\right)$ was bought from Sigma-Aldrich. Luviskol ${ }^{\circledR}$ VA 64, a poly(vinylpyrrolidone-co-vinyl acetate) (PVP/VA) mixture was kindly gifted by BASF.

\section{Method}

$1 \mathrm{~g}$ of PVP/VA and $0.1 \mathrm{~g}$ of silver nitrate is dissolved in $50 \mathrm{~mL}$ of absolute ethanol. $0.02 \mathrm{~g}$ of sodium borohydride and $0.2 \mathrm{~g}$ of $\mathrm{PVP} / \mathrm{VA}$ dissolved in $10 \mathrm{~mL}$ of absolute ethanol is added to the solution at one drop per second under vigorously stirring. $30 \mathrm{~s}$ after complete addition the stirring is stopped.

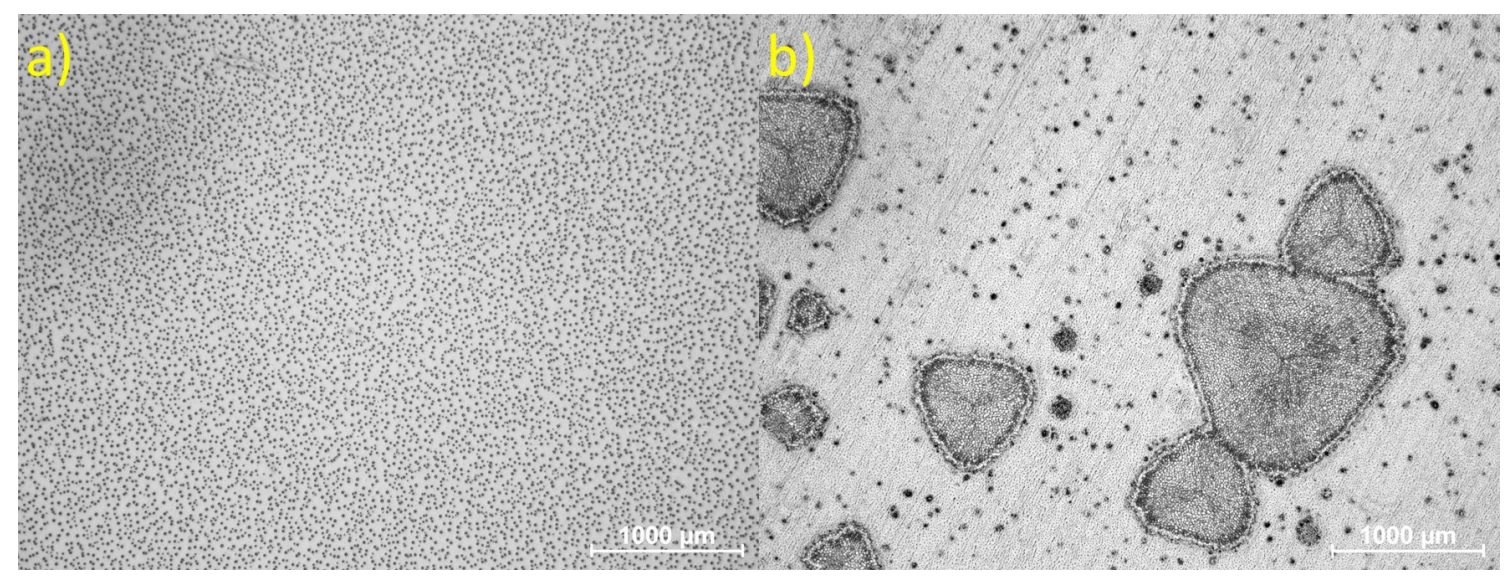

Figure 6: Microscope images at $2.5 \times$ magnification of SU-8 nanocomposites after post-exposure bake at $95{ }^{\circ} \mathrm{C}$; a) with $250 \mathrm{mg} \cdot \mathrm{mL}^{-1}$ of $\mathrm{AgNO}_{3}$ precursor solution added and b) $500 \mathrm{mg} \cdot \mathrm{mL}^{-1}$ of $\mathrm{AgNO}_{3}$ precursor solution added. 


\section{Solvent exchange}

The solvent exchange is done using a rotary evaporator Rotavapor $^{\circledR}$ R-210 from Büchi.

1. $10 \mathrm{~mL}$ of the nanoparticle solution is attached to the rotary evaporator and $1 \mathrm{~mL}$ of ethanol evaporated.

2. $1 \mathrm{~mL}$ of cyclopentanone is added to the solution.

3. $3 \mathrm{~mL}$ of ethanol is evaporated and $1 \mathrm{~mL}$ of cyclopentanone added.

4. The remaining $6 \mathrm{~mL}$ of ethanol is evaporated and $1 \mathrm{~mL}$ cyclopentanone added.

\section{Acknowledgements}

This work is supported by the Copenhagen Cleantech Cluster and the DTU - KAIST IWT project.

\section{References}

1. Daniel, M.-C.; Astruc, D. Chem. Rev. 2004, 104, 293-346. doi:10.1021/cr030698+

2. Overview. In Metal Nanoparticles: Synthesis, Characterization, and Applications; Fedlheim, D. L.; Foss, C. A., Eds.; Marcel Dekker, Inc.: New York, 2002; pp 1-15.

3. Yaklin, M. A.; Duxbury, P. M.; Mackay, M. E. Soft Matter 2008, 4, 2441-2447. doi:10.1039/b807565d

4. Wei, G.; Bhushan, B.; Ferrell, N.; Hansford, D. J. Vac. Sci. Technol., A 2005, 23, 811-819. doi:10.1116/1.1861937

5. Gray, B. J. Electrochem. Soc. 2014, 161, B3173-B3183. doi:10.1149/2.023402jes

6. Chung, D.; Khosla, A.; Gray, B. L.; Parameswaran, A. M.; Ramaseshan, R.; Kohli, K. J. Electrochem. Soc. 2014, 161, B3071-B3076. doi:10.1149/2.018402jes

7. Mizeikis, V.; Juodkazis, S.; Tarozaitè, R.; Juodkazyté, J.; Juodkazis, K.; Misawa, H. Opt. Express 2007, 15, 8454-8464. doi:10.1364/OE.15.008454

8. LaBianca, N. C.; Gelorme, J. D. High-aspect-ratio resist for thick-film applications. In Proceedings of SPIE: Advances in Resist Technology and Processing XII, Santa Clara, CA, Feb 19, 1995; Allen, R. D., Ed.; pp 846-852. doi:10.1117/12.210413

9. Serbin, J.; Ovsianikov, A.; Chichkov, B. Opt. Express 2004, 12, 5221-5228. doi:10.1364/OPEX.12.005221

10. Nemani, K. V.; Moodie, K. L.; Brennick, J. B.; Su, A.; Gimi, B. Mater. Sci. Eng., C 2013, 33, 4453-4459. doi:10.1016/j.msec.2013.07.001

11. Chen, Y.-S.; Tal, A.; Kuebler, S. M. Chem. Mater. 2007, 19, 3858-3860. doi:10.1021/cm0710812

12. Flack, W. W.; Soong, D. S.; Bell, A. T.; Hess, D. W. J. Appl. Phys. 1984, 56, 1199-1206. doi:10.1063/1.334049

13. Jiguet, S.; Bertsch, A.; Hofmann, H.; Renaud, P. Adv. Eng. Mater. 2004, 6, 719-724. doi:10.1002/adem.200400068

14. Jiguet, S.; Bertsch, A.; Hofmann, H.; Renaud, P. Adv. Funct. Mater. 2005, 15, 1511-1516. doi:10.1002/adfm.200400575

15. Keller, S.; Blagoi, G.; Lillemose, M.; Haefliger, D.; Boisen, A. J. Micromech. Microeng. 2008, 18, 125020. doi:10.1088/0960-1317/18/12/125020

16. Bohren, C. F.; Huffmann, D. R. Absorption and Scattering of Light by Small Particles; Wiley-VCH: Weinheim, Germany, 1983.

17. Fang, Y. J. Chem. Phys. 1998, 108, 4315-4318. doi:10.1063/1.475831
18. del Campo, A.; Greiner, C. J. Micromech. Microeng. 2007, 17, R81-R95. doi:10.1088/0960-1317/17/6/R01

\section{License and Terms}

This is an Open Access article under the terms of the Creative Commons Attribution License (http://creativecommons.org/licenses/by/2.0), which permits unrestricted use, distribution, and reproduction in any medium, provided the original work is properly cited.

The license is subject to the Beilstein Journal of Nanotechnology terms and conditions: (http://www.beilstein-journals.org/bjnano)

The definitive version of this article is the electronic one which can be found at: doi:10.3762/bjnano.6.168 